\title{
Precise lead isotope ratios in Australian galena samples by high resolution inductively coupled plasma mass spectrometry
}

\author{
Ashley T. Townsend ${ }^{* a}$, Zongshou Yu ${ }^{b}$, Peter McGoldrick ${ }^{b}$ and James A. Hutton ${ }^{a}$ \\ ${ }^{a}$ Central Science Laboratory, University of Tasmania, GPO Box 252-74, Hobart, Tasmania, 7001, Australia \\ ${ }^{b}$ Centre for Ore Deposits and Exploration Studies, University of Tasmania, GPO Box 252-79, Hobart, Tasmania, 7001, Australia
}

\begin{abstract}
High resolution inductively coupled plasma mass spectrometry (HR-ICP-MS) was used to measure $\mathrm{Pb}$ isotope ratios in standard solutions and $\mathrm{Pb}$ mineral digests. The $\mathrm{RSD}$ values obtained for ${ }^{208} \mathrm{~Pb} /{ }^{204} \mathrm{~Pb},{ }^{207} \mathrm{~Pb} /{ }^{204} \mathrm{~Pb},{ }^{206} \mathrm{~Pb} /{ }^{204} \mathrm{~Pb},{ }^{208} \mathrm{~Pb} /{ }^{206} \mathrm{~Pb}$ and ${ }^{207} \mathrm{~Pb} /{ }^{206} \mathrm{~Pb}$ were $0.13,0.11,0.11,0.046$ and $0.048 \%$, respectively (values as $1 \sigma$ ). These values were obtained from 30 analyses of three different standard sample types (multielement standard, NIST SRM 981 and a Broken Hill galena digest). Based on 39 analyses of 11 galena samples from different locations around Australia, the difference between HR-ICP-MS and conventional TIMS values for ${ }^{208} \mathrm{~Pb} /{ }^{204} \mathrm{~Pb}$, ${ }^{207} \mathrm{~Pb} /{ }^{204} \mathrm{~Pb},{ }^{206} \mathrm{~Pb} /{ }^{204} \mathrm{~Pb},{ }^{208} \mathrm{~Pb} /{ }^{206} \mathrm{~Pb}$ and ${ }^{207} \mathrm{~Pb} /{ }^{206} \mathrm{~Pb}$ ratios was generally better than $\pm 0.2 \%$. This paper outlines a very simple and rapid analytical method for the measurement of $\mathbf{P b}$ isotope ratios, and is one of the first studies to use HR-ICP-MS to measure $\mathrm{Pb}$ isotope ratios in galena and galena-bearing ores.
\end{abstract}

Keywords: Lead isotope ratios; high resolution inductively coupled plasma mass spectrometry; galena; ores

The study of the isotopic composition of $\mathrm{Pb}$ in rocks and minerals began over 80 years ago and was initially used as a geochronological tool. ${ }^{1}$ Subsequent work showed that for many types of geological materials, $\mathrm{Pb}$ isotope geochronology was complicated by the presence of 'common' $\mathrm{Pb}$ (i.e., nonradiogenic $\mathrm{Pb}$ ). ${ }^{2}$ Hence today, $\mathrm{Pb}$ isotope geochronology uses minerals that formed with very little $\mathrm{Pb}{ }^{3}$ However, a second important practical application of $\mathrm{Pb}$ isotopes is in studying and exploring for mineral deposits. ${ }^{4}$ The $\mathrm{Pb}$ isotope composition of rocks and $\mathrm{Pb}$-bearing minerals can be used to trace the sources of metal in ores and to help discriminate barren from mineralised ore systems.

At present, thermal ionisation mass spectrometry (TIMS) is the technique of choice for all types of geological $\mathrm{Pb}$ isotope measurements. However, the relatively high cost of TIMS instrumentation and the (necessary) extensive chemical pretreatment of the sample prior to analysis have imposed serious limitations on the routine use of TIMS techniques in geochemical exploration applications.

Quadrupole based ICP-MS instruments have been used in many studies to measure $\mathrm{Pb}$ isotope ratios. ${ }^{5-8}$ However, owing to the design and manner in which quadrupole mass analysers operate, the technique has been found to be limited in both precision and accuracy. The precision of isotope ratios measured on quadrupole ICP-MS instruments is typically $0.1 \%$ $\mathrm{RSD}$, whereas for ratios involving a low abundance isotope such as ${ }^{204} \mathrm{~Pb}$, a precision of $0.2-1 \%$ RSD is usually obtained. ${ }^{8}$

Recently, Begley and Sharp ${ }^{8}$ undertook an elegant study of $\mathrm{Pb}$ isotope ratios using a quadrupole ICP-MS instrument.
After careful consideration of all possible causes of instrumental bias, the precision obtained from the analysis of NIST Standard Reference Material (SRM) 981 Natural Lead ranged from 0.04 to $0.12 \%$, depending on the ratio considered. The accuracy and precision reported may be the best obtained from a quadrupole instrument. However, the methodology and detail required to obtain such results could not be called routine.

High resolution ICP-MS (HR-ICP-MS) is a relatively new technique employing a magnetic sector mass analyser. To date it has been applied in a variety of areas such as environmental and biological analysis and the monitoring of radionuclides (see the review by Becker and Dietze ${ }^{9}$ ). Only a limited number of studies have been reported on measuring isotope ratios. ${ }^{10-14}$ With regard to $\mathrm{Pb}$ isotope ratios, Vanhaecke et al. ${ }^{10}$ obtained a precision of $0.04 \%(n=10)$ for the ${ }^{206} \mathrm{~Pb} /{ }^{207} \mathrm{~Pb}$ ratio in a standard lead solution. Little has been reported about the $\mathrm{Pb}$ isotope ratio analysis of geological matrices. ${ }^{14}$ It should also be noted, however, that double focusing multiple collector ICP-MS instruments have been used recently to measure highly accurate isotope ratios (including $\mathrm{Pb}$ ), and may see increased use in future work. ${ }^{15,16}$

In this paper, a fast and reliable method for the precise measurement of $\mathrm{Pb}$ isotope ratios in geological samples by HR-ICP-MS is reported. The technique was applied to the measurement of the $\mathrm{Pb}$ isotope composition of galena and galena-bearing ores from Broken Hill and Western Tasmania, previously measured by TIMS.

\section{EXPERIMENTAL}

\section{Reagents}

High purity $\mathrm{HCl}$ was prepared by doubly quartz distilling analytical-reagent grade acid (Merck, Darmstadt, Germany), and high purity HF was prepared from analytical-reagent grade acid (Merck) that had been further purified via a Teflon distillation system. High purity $\mathrm{HNO}_{3}$ (Mallinckrodt, St. Louis, MO, USA) was used as received for sample digestion and solution acidification. Ultra-pure de-ionised water $(\geq 18 \mathrm{M} \Omega$ ) was prepared via a glass distillation unit followed by further purification with a Modulad water purification system (Continental Water System, Melbourne, Australia).

\section{Standards and sample preparation}

Instrument tuning and general $\mathrm{Pb}$ solutions were prepared by dilution from a Perkin-Elmer (Norwalk, CT, USA) $10 \mu \mathrm{g} \mathrm{g}^{-1}$ multi-element solution containing Pb (Cat. No. N930-0233).

A stock standard solution of NIST SRM 981 Natural Lead was prepared by dissolving $0.05 \mathrm{~g}$ of $\mathrm{Pb}$ in $5 \mathrm{ml}$ of dilute $\mathrm{HNO}_{3}(1+4)$ with heating in a Savillex screw-topped Teflon 
beaker. ${ }^{17}$ After cooling to room temperature, $1 \mathrm{ml}$ of concentrated $\mathrm{HNO}_{3}$ was added before dilution to $100 \mathrm{ml}$ total volume (in polycarbonate). The stock standard solution was diluted to working concentrations (generally $10-50 \mathrm{ng} \mathrm{g}^{-1}$ ) before analysis. This reference solution was used as the external calibration standard in this study.

Galena sample solutions were prepared as follows. Samples were dried at $105^{\circ} \mathrm{C}$ overnight and $0.1 \mathrm{~g}$ portions were added to Savillex screw-topped Teflon beakers. A $5 \mathrm{ml}$ volume of $\mathrm{HF}-\mathrm{HNO}_{3}-\mathrm{HCl}(2+1+3)$ acid mixture was added to each sample ${ }^{18}$ with overnight heating on a hot-plate at $130^{\circ} \mathrm{C}$. The resulting solution was twice evaporated to incipient dryness, with the addition of $1 \mathrm{ml}$ of $\mathrm{HNO}_{3}$ after each drying stage. All solutions were stored in sealed polycarbonate containers. Galena solutions were diluted to a $\mathrm{Pb}$ concentration between 40 and $50 \mathrm{ng} \mathrm{g}^{-1}$ for HR-ICP-MS analysis.

\section{Instrumentation}

$\mathrm{Pb}$ isotope ratios were measured on an Element HR-ICP-MS instrument (Finnigan MAT, Bremen, Germany). This instrument, utilising a magnetic sector mass analyser of reversed Nier-Johnson geometry, has pre-defined resolution settings ( $\mathrm{m} / \Delta \mathrm{m}$ at $10 \%$ valley definition) of 300 (low), 3000 (medium) and 7500 (high). A resolution of 300 was used in this work, providing flat-topped peaks and maximum instrument sensitivity (typically greater than $10^{6}$ counts $\mathrm{s}^{-1}$ for $10 \mathrm{ng} \mathrm{g}^{-1}{ }^{115} \mathrm{In}$ or $7 \times 10^{5}$ counts $\mathrm{s}^{-1}$ for $10 \mathrm{ng} \mathrm{g}^{-1}{ }^{208} \mathrm{~Pb}$ ). Instrument and method settings are outlined in Tables 1 and 2. A standard Meinhard nebuliser and Scott double pass water cooled spray chamber were employed. Isotopes of interest were analysed using electric scanning with the magnet held at fixed mass. The secondary electron multiplier detector (with discrete dynodes) was operated in the counting mode. Instrument tuning and optimisation were performed daily using a $10 \mathrm{ng}$ $\mathrm{g}^{-1}$ multi-element solution containing $\mathrm{Pb}$. Further details concerning this instrument have been reported elsewhere. ${ }^{19-21}$

All isotope ratio values were adjusted for instrument dead time. $^{22}$ Each $\mathrm{Pb}$ isotope ratio was considered in dead time determinations. The dead time was measured regularly throughout the study using three $\mathrm{Pb}$ solutions of different concentrations, namely 10,25 and $50 \mathrm{ng} \mathrm{g}^{-1} \mathrm{~Pb}$. Dead time values in the range $20-50 \mathrm{~ns}$ were typically found, depending on the detector settings. Analyses were also blank corrected.

\section{Table 1 Typical instrumental configuration and settings}

Instrument

Resolution $(m / \Delta m)$

Rf power

Nebuliser

Coolant argon flow rate

Auxiliary argon flow rate

Nebuliser argon flow rate

Spray chamber

Sampler cone

Skimmer cone

Instrument tuning

Ion transmission

Scan type

Ion sampling depth

Ion lens settings

Finnigan MAT Element
300 (low)
$1250 \mathrm{~W}$
Meinhard concentric
$\sim 12.51 \mathrm{~min}^{-1 *}$
$\sim 1.11 \mathrm{~min}^{-1 *}$
$\sim 1.11 \mathrm{~min}^{-1 *}$
Scott (double pass) type cooled
to $3.5-5^{\circ} \mathrm{C}$
Nickel, $1.1 \mathrm{~mm}$ aperture id
Nickel, $0.8 \mathrm{~mm}$ aperture id
Performed using a $10 \mathrm{ng} \mathrm{g}^{-1}$
multi-element solution
Typically $10^{6}$ counts $\mathrm{s}^{-1}$ per $10 \mathrm{ng} \mathrm{g}^{-1}$
115 In or $7 \times 10^{5}$ counts $\mathrm{s}^{-1}$ for
$10 \mathrm{ng}^{-1} 208 \mathrm{~Pb}$
Fixed magnet with electric scan over
small mass range
Adjusted daily*
Adjusted daily $\dagger$

* Adjusted in order to obtain maximum signal intensity. † Adjusted in order to obtain maximum signal intensity and optimum resolution.

Table 2 Method parameters for $\mathrm{Pb}$ isotope ratio measurements

Isotopes considered

Scan type

Mass scanning window

Magnet settle time

Dwell time per measurement

Scan duration per sweep

Number of sweeps

Measurement time

per replicate

Detector mode

Integration type

Sample uptake and equilibration time

Rinse time between each sample

Total time per sample

Measured dead time

${ }^{201} \mathrm{Hg}$ or ${ }^{202} \mathrm{Hg},{ }^{204} \mathrm{~Pb},{ }^{206} \mathrm{~Pb},{ }^{207} \mathrm{~Pb}$
and ${ }^{208} \mathrm{~Pb}$
Magnet fixed at ${ }^{201} \mathrm{Hg}$. Electric scans
over other mass ranges
$3 \%$
$0.1 \mathrm{~s}$
$0.001 \mathrm{~s}$
$5 \times 0.025 \mathrm{~s}$
2000
$250 \mathrm{~s}$
Counting
Average
2 min
$3-5$ min (with $5 \% \mathrm{HNO}_{3}$ )
$\sim 15$ min
In the range $20-50 \mathrm{~ns}$, depending on
detector settings

\section{RESULTS AND DISCUSSION}

\section{Mass discrimination correction}

Isotope ratio values obtained using ICP-MS may deviate from the 'true' value as a function of the difference in mass between the two isotopes measured. This effect is defined as mass bias and its value may be either positive or negative. ${ }^{23}$ The bias or discrimination can only be determined experimentally and will vary with the configuration of the individual ICP-MS system. ${ }^{22}$ In this study, instrument mass discrimination was corrected by the use of a NIST SRM 981 external standard. Unknown samples to be measured were typically analysed between alternate standard reference solutions. The use of this correction method allows any measured differences in a $\mathrm{Pb}$ standard sample to correct the ratios found in unknown $\mathrm{Pb}$ solutions (i.e., $\mathrm{Pb}$ standards correcting for $\mathrm{Pb}$ unknowns). Also, similar isotope abundances are typically measured for both standards and unknowns. However, on the negative side, there is a time delay between each standard and sample in which changes in plasma conditions can occur. The other option of using a Tl internal standard for mass discrimination correction was not investigated in this study. This method involves measuring another isotope $(\mathrm{Tl})$ which may behave in a different fashion to $\mathrm{Pb}$ whilst also increasing the analysis time for each scan (time which could be spent accumulating $\mathrm{Pb}$ data). The internal correction approach has an advantage, however, of continuously monitoring the mass discrimination for each individual sample. Both methods have been used in previous $\mathrm{Pb}$ isotope studies $^{6-8,11}$ and were outlined in detail by Begley and Sharp. ${ }^{8}$

\section{General analytical and methodology considerations}

Method parameters were systematically varied and tested in order to obtain the most accurate and precise $\mathrm{Pb}$ isotope ratios. The first variable considered was the number of scans for each sample. The ideal situation would be to acquire as many scans as possible in the shortest time interval, hence approaching the behaviour of a multiple collector system. The number of sweeps across the $\mathrm{Pb}$ isotopes was varied between 500 (total analysis time $62.5 \mathrm{~s}$ ) and $3000(375 \mathrm{~s})$, with 2000 scans ( $250 \mathrm{~s}$ ) proving optimum considering $\mathrm{Pb}$ signal stabilities. All scanning protocols were at a rate of 8 sweeps $\mathrm{s}^{-1}$, keeping the dwell time for each mass segment constant. Vanhaecke et al. ${ }^{10}$ used 1200 scans in 2 min to measure ${ }^{206} \mathrm{~Pb} /{ }^{207} \mathrm{~Pb}$ isotope ratios in a standard $\mathrm{Pb}$ solution.

Vanhaecke et al. ${ }^{11}$ also found that when considering both $\mathrm{Pb}$ or $\mathrm{Cu}$ isotope ratios at resolution 3000 using HR-ICP-MS, 


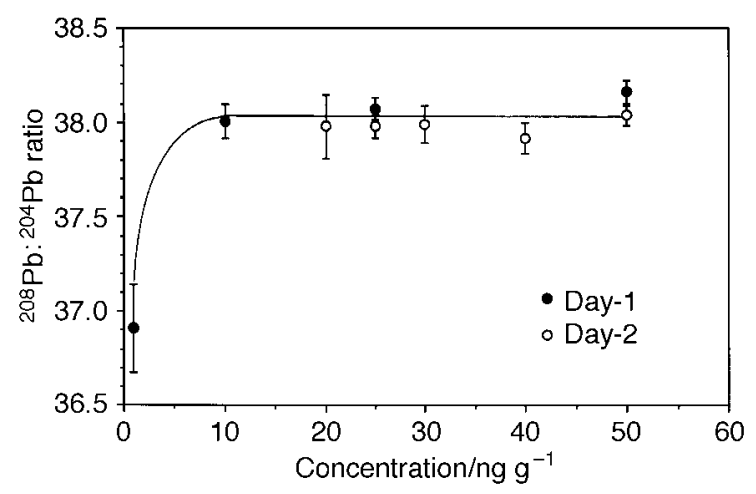

Fig. 1 Measured ${ }^{208} \mathrm{~Pb} /{ }^{204} \mathrm{~Pb}$ ratios versus $\mathrm{Pb}$ concentration in standard solutions. Ratios were measured over two consecutive days. Note that the values shown have not been corrected for any mass discrimination.

the precision was improved when the mass scanning window was reduced from 20 to $10 \%$ (the percentage window value is based on the expected mass width of a peak in the respective resolution). It was suggested that when smaller mass windows were used, only the centre of each peak was scanned, minimising the influence of any mass calibration instabilities. Although more crucial at resolution 3000 away from the flat-topped peaks of resolution 300, a similar systematic study was undertaken in this work, considering $\mathrm{Pb}$ ratios at low resolution. Mass windows between 1 and $10 \%$ were considered, and it was found that a mass scanning window of $3 \%$ gave isotope signals with minimum variation over the total number of scans.

The working $\mathrm{Pb}$ concentration range for which accurate $\mathrm{Pb}$ isotope ratios could be obtained was also investigated. At $\mathrm{Pb}$ concentrations below $10 \mathrm{ng} \mathrm{g}^{-1}$, ratios with ${ }^{204} \mathrm{~Pb}$ as the basis were found to be limited by counting statistics, resulting in less accurate results (a concentration of $10 \mathrm{ng} \mathrm{g}^{-1}$ corresponded to approximately 15000 counts $\mathrm{s}^{-1}$ of ${ }^{204} \mathrm{~Pb}$ ). This is shown more clearly in Fig. 1 for the ${ }^{208} \mathrm{~Pb} /{ }^{204} \mathrm{~Pb}$ ratio measured in $\mathrm{Pb}$ standard solutions of various concentrations analysed over two consecutive days. Similar results were found for the other $\mathrm{Pb}$ ratios considered. This has not been noted as a problem in other HR-ICP-MS studies as the ratios investigated have typically involved ${ }^{206} \mathrm{~Pb},{ }^{207} \mathrm{~Pb}$ and ${ }^{208} \mathrm{~Pb}$ isotopes only. ${ }^{10,14}$ At the other extreme, $\mathrm{Pb}$ concentrations above $50 \mathrm{ng} \mathrm{g}^{-1}$ were not considered as the signal from ${ }^{208} \mathrm{~Pb}$ required measurement in the analogue detector mode to avoid detector saturation (under normal operating conditions and detector settings, $50 \mathrm{ng} \mathrm{g}^{-1}$ of ${ }^{208} \mathrm{~Pb}$ corresponded to $3 \times 10^{6}-3.5 \times 10^{6}$ counts $\left.\mathrm{s}^{-1}\right)$. Rather than limit the accuracy of the ratio determinations it was decided to make all measurements in the same detector mode (counting). Hence ratios were only determined in the $\mathrm{Pb}$ concentration range $10-50 \mathrm{ng} \mathrm{g}^{-1}$. Work is continuing to increase the concentration range for which accurate $\mathrm{Pb}$ ratios can be obtained.

All ratio measurements were dead time corrected. Even with this adjustment, it was found that the accuracy of each measurement could be further improved when the $\mathrm{Pb}$ concentration in the NIST SRM 981 external calibration standard and the unknown sample were closely matched. As such the concentration of $\mathrm{Pb}$ in each sample was often adjusted prior to ratio determinations.

Along with the four $\mathrm{Pb}$ isotopes of interest, ${ }^{202} \mathrm{Hg}$ and ${ }^{201} \mathrm{Hg}$ were also measured as ${ }^{204} \mathrm{~Pb}(1.4 \%$ abundant $)$ has an isobaric interference from ${ }^{204} \mathrm{Hg}(6.85 \%$ abundant $)$ in resolution 300 . For geological samples that were previously ground in tungsten crushing mills, ${ }^{201} \mathrm{Hg}$ was used to correct ${ }^{204} \mathrm{~Pb}$, as ${ }^{202} \mathrm{Hg}$ suffers interference by ${ }^{186} \mathrm{~W}^{16} \mathrm{O} .{ }^{7}$ For other samples ${ }^{202} \mathrm{Hg}$ was used. It was expected that during sample digestion any volatile $\mathrm{Hg}$ would be driven off during the multiple drying stages, while the $\mathrm{Hg}: \mathrm{Pb}$ ratio in rocks and sulfides is generally low $(1: 10-100))^{24}$ No samples analysed in this study were found to have appreciable levels of $\mathrm{Hg}$ or $\mathrm{W}$. However, it was important to include these isotopes in method development work for future samples when more appreciable $\mathrm{Hg}$ or $\mathrm{W}$ concentrations may be encountered.

\section{Precision}

Lead isotope ratio precision data for 10 consecutive measurements of three different standard solutions are given in Table 3 . Precisions obtained for ratios involving the low abundance ${ }^{204} \mathrm{~Pb}$ isotope were $0.10-0.13 \%$ for ${ }^{208} \mathrm{~Pb} /{ }^{204} \mathrm{~Pb}, 0.10-0.11 \%$ for ${ }^{207} \mathrm{~Pb} /{ }^{204} \mathrm{~Pb}$ and $0.10-0.11 \%$ for ${ }^{206} \mathrm{~Pb} /{ }^{204} \mathrm{~Pb}$ (values as $1 \sigma$ ). Improved precisions were found for those ratios involving the more abundant isotopes, namely $0.041-0.046 \%$ for ${ }^{208} \mathrm{~Pb} /{ }^{206} \mathrm{~Pb}$ and $0.044-0.048 \%$ for ${ }^{207} \mathrm{~Pb} /{ }^{206} \mathrm{~Pb}$. No difference in measurement precision was apparent between standard $\mathrm{Pb}$ solutions and more 'complex' galena digest samples. Theoretical precisions based on Poisson counting statistics were also calculated and are shown in Table 3 (based on ${ }^{208} \mathrm{~Pb}$ signals of the order of $1 \times 10^{6}-3 \times 10^{6}$ counts $\mathrm{s}^{-1}$ ). In agreement with other workers, ${ }^{13}$ external precisions approximately $2-3$ times greater than that predicted from counting statistics alone were found, suggesting noise contributions from other sources such as the sample introduction system and plasma flicker. The precisions obtained for ratios referenced to ${ }^{206} \mathrm{~Pb}$ are similar to that found by Vanhaecke et al. ${ }^{10}$ using a similar HR-ICP-MS instrument to measure the ${ }^{206} \mathrm{~Pb} /{ }^{207} \mathrm{~Pb}$ ratio of a standard $\mathrm{Pb}$ solution. The external precisions given in Table 3 are also similar to the best obtained using a quadrupole ICP-MS by Begley and Sharp. ${ }^{8}$

Table $3 \mathrm{~Pb}$ isotope ratio precision and accuracy data for a standard multi-element solution, NIST SRM 981 and a Broken Hill galena digest. Samples were analysed at a $\mathrm{Pb}$ concentration of $45 \mathrm{ng} \mathrm{g}^{-1}$

Multi-element standard solution-

Precision for 10 measurements, RSD (\%)

Theoretical RSD $(\%) *$

NIST SRM 981 Natural Lead-

Precision for 10 measurements, RSD (\%)

Theoretical RSD (\%)*

Broken Hill galena-

Measured ratio

Reference value $\dagger$

ICP-MS bias from TIMS value (\%)

Precision for 10 measurements, RSD (\%)

Theoretical RSD (\%)*

* From Poisson counting statistics.

$$
{ }^{208} \mathrm{~Pb} /{ }^{204} \mathrm{~Pb}
$$

\subsection{1}

0.054

0.10

0.049

35.520

35.599

$-0.22$

0.13

0.052
${ }^{207} \mathrm{~Pb} /{ }^{204} \mathrm{~Pb}$

0.11

0.055

0.11

0.050

15.353

15.370

$-0.11$

0.10

0.053

${ }^{208} \mathrm{~Pb} /{ }^{206} \mathrm{~Pb}$
0.041
0.015

0.046
0.014

2.222
2.226
-0.18
0.043
0.015

${ }^{207} \mathrm{~Pb} /{ }^{206} \mathrm{~Pb}$

0.047

0.016

0.048

0.015

0.961

0.961

0

0.044

0.016 


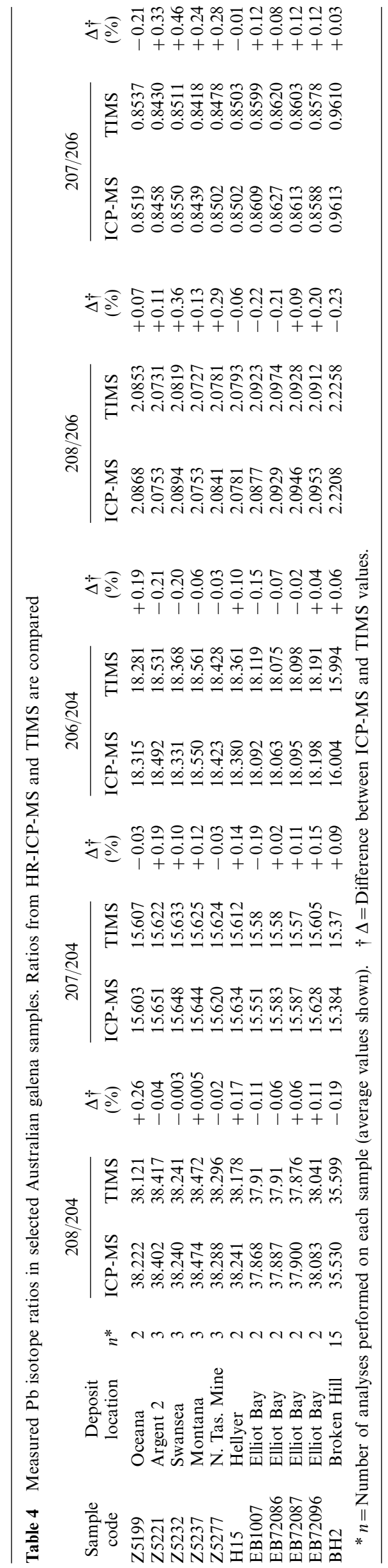




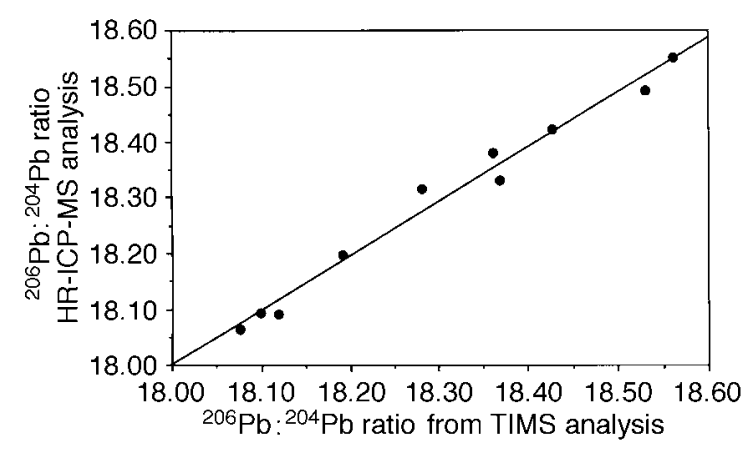

Fig. 2 Comparison between average ${ }^{206} \mathrm{~Pb} /{ }^{204} \mathrm{~Pb}$ ratio values obtained via HR-ICP-MS and TIMS techniques (for purposes of scale the Broken Hill galena sample has been omitted).

\section{Comparison with TIMS values and accuracy of the analytical method}

In order to study the accuracy of the present method, the $\mathrm{Pb}$ isotope ratios of 11 galena and galena-rich ore samples were measured by TIMS at CSIRO North Ryde and by HR-ICP-MS at the University of Tasmania. Samples were typically analysed 2-3 times by HR-ICP-MS, with the $\mathrm{Pb}$ concentration of the NIST SRM 981 external calibration standard and the unknown $\mathrm{Pb}$ sample being closely matched. Comparative data are given in Table 4. There is very good agreement between the two techniques and this is highlighted in Fig. 2, showing HR-ICP-MS values for the ${ }^{206} \mathrm{~Pb} /{ }^{204} \mathrm{~Pb}$ ratio plotted against TIMS data $\left({ }^{206} \mathrm{~Pb} /{ }^{204} \mathrm{~Pb}\right.$ HR-ICP-MS $=0.98 \times{ }^{206} \mathrm{~Pb} /{ }^{204} \mathrm{~Pb}_{\text {TIMS }}+$ $0.45, r^{2}=0.983$ for $\left.n=10\right)$. The ratio precision from HR-ICP-MS was about $0.05 \%$ and that from TIMS was about $0.02-0.05 \%{ }^{15} \mathrm{~A}$ similar figure was presented in work by Date and Cheung ${ }^{6}$ using an early model quadrupole ICP-MS. The difference in $\mathrm{Pb}$ ratio values between the two analytical techniques was generally less than $\pm 0.2 \%$, and was in the range $0.001-0.1$ for ${ }^{208} \mathrm{~Pb} /{ }^{204} \mathrm{~Pb}, \quad 0.004-0.03$ for ${ }^{207} \mathrm{~Pb} /{ }^{204} \mathrm{~Pb}$, $0.003-0.04$ for ${ }^{206} \mathrm{~Pb} /{ }^{204} \mathrm{~Pb}, 0.001-0.008$ for ${ }^{208} \mathrm{~Pb} /{ }^{206} \mathrm{~Pb}$ and $0.0001-0.004$ for ${ }^{207} \mathrm{~Pb} /{ }^{206} \mathrm{~Pb}$.

\section{Geological implications}

Lead isotopes are powerful tools in exploration for mineral deposits and the investigation of problems of ore genesis. ${ }^{4}$ However, unlike multi-element geochemical analyses, they are not commonly used when exploring for new deposits owing to the expense of TIMS analysis. From an earlier study, ${ }^{4}$ the Cambrian volcanogenic massive sulfide (VMS) and postCambrian (Post C) mineralisation in Western Tasmania can be clearly separated when the $\mathrm{Pb}$ isotope ratio precision is less than \pm 0.1 for ${ }^{208} \mathrm{~Pb} /{ }^{204} \mathrm{~Pb}$ and \pm 0.05 for ${ }^{207} \mathrm{~Pb} /{ }^{204} \mathrm{~Pb}$ and ${ }^{206} \mathrm{~Pb} /{ }^{204} \mathrm{~Pb}$ (in terms of absolute ratio units). Our work has shown that $\mathrm{Pb}$ isotope ratios can be measured relatively quickly by HR-ICP-MS to a precision approaching that obtained by TIMS on the same mixed acid digestion solutions normally used in commercial geochemical analyses. This results in a reduction in cost when compared with TIMS measurements, and opens up the possibility of the routine use of $\mathrm{Pb}$ isotopes in geochemical exploration surveys for new mineral deposits.

\section{CONCLUSION}

This work has clearly shown that under routine operating conditions, precise and accurate $\mathrm{Pb}$ isotope ratios can be measured in $\mathrm{Pb}$ mineral concentrates using HR-ICP-MS. Based on the analysis of a series of standard reference solutions, this comparatively fast analytical method provided $\mathrm{Pb}$ ratios with precisions of $0.13 \%$ RSD or better for ratios to ${ }^{204} \mathrm{~Pb}$. For ratios to ${ }^{206} \mathrm{~Pb}$, the precisions obtained were of the order of $0.045 \%$. TIMS and HR-ICP-MS were found to be in agreement to an accuracy of $\pm 0.2 \%$, irrespective of the ratio considered. This level of accuracy is adequate for many geochemical applications. The relative ease and speed with which these values were obtained suggest that HR-ICP-MS may see increased use for geochemical $\mathrm{Pb}$ isotope ratio measurements.

The authors acknowledge the facilities and support provided by the Central Science Laboratory and Centre for Ore Deposits and Exploration Studies (CODES), University of Tasmania. Ross Large, Paul Kitto, Bruce Gemmel and David Steele are thanked for their support, samples and related information.

\section{REFERENCES}

1 Holmes, A., The Age of the Earth, Harper, New York, 1913, p. 194.

2 Faure, G., Principles of Isotope Geology, Wiley, New York, 1977, p. 464

3 Schaltegger, U., Schneider, J. L., Maurin, J. C., and Corfu, F., Earth Planet. Sci. Lett., 1996, 144, 403.

4 Gulson, B. L., Lead Isotopes in Mineral Exploration, Elsevier, Amsterdam, 1986, p. 245.

5 Smith, R. G., Brooker, E. J., Douglas, D. J., Quan, E. S. K., and Rosenblatt, G., J. Geochem. Explor., 1984, 21, 385.

6 Date, A. R., and Cheung, Y. Y., Analyst, 1987, 112, 1531.

7 Longerich, H. P., Wilton, D. H. C., and Fryer, B. J., J. Geochem. Explor., 1992, 43, 111

8 Begley, I. S., and Sharp, B. L., J. Anal. At. Spectrom., 1997, 12, 395.

9 Becker, J. S., and Dietze, H.-J., J. Anal. At. Spectrom., 1997, 12, 881.

10 Vanhaecke, F., Moens, L., and Dams, R., Anal. Chem., 1996, 68, 567.

11 Vanhaecke, F., Moens, L., Dams, R., Papadakis, I., and Taylor, P., Anal. Chem., 1997, 69, 268.

12 Cornec, F. L., and Correge, T., J. Anal. At. Spectrom., 1997, 12, 969.

13 Stürup, S., Hansen, M., and Mølgaard, C., J. Anal. At. Spectrom., 1997, 12, 919

14 Shuttleworth, S., Morris, J., Crombie, K., Ridings, R., and Arvidson, R., in Proceedings of the 3rd International Conference on the Analysis of Geological and Environmental Materials, Colorado, USA, June 1997, p. 100.

15 Walder, A. J., Platzner, I., and Freedman, P. A., J. Anal. At. Spectrom., 1993, 8, 19 .

16 Walder, A. J., and Furuta, N., Anal. Sci., 1993, 9, 675.

17 Potts, P. J., A Handbook of Silicate Rock Analysis, Blackie, Glasgow, 1987, p. 622.

18 Chao, T. T, and Sanzolone, R. F., J. Geochem. Explor., 1992, 44, 65

19 Feldmann, I., Tittes, W., Jakubowski, N., Stuewer, D., and Giessmann, U., J. Anal. At. Spectrom., 1994, 9, 1007.

20 Moens, L., Verrept, P., Dams, R., Greb, U., Jung, G., and Laser, B., J. Anal. At. Spectrom., 1994, 9, 1075.

21 Moens, L., Vanhaecke, F., Riondato, J., and Dams, R., J. Anal. At. Spectrom., 1995, 10, 569.

22 Price Russ, G., in Applications of Inductively Coupled Plasma Mass Spectrometry, ed. Date, A. R., and Gray, A. L., Blackie, Glasgow, 1989, pp. 90-110.

23 Jarvis, K. E., Gray, A. L., and Houk, R. S., Handbook of Inductively Coupled Plasma Mass Spectrometry, Blackie, Glasgow, 1992 , p. 380

24 Sewell, D. M., and Wheatley, C. J. V., J. Geochem. Explor., 1994, 50, 351 . 